\title{
Métodos de Coleta de Fezes e Determinação dos Coeficientes de Digestibilidade da Fração Protéica e da Energia de Alimentos para o Pacu, Piaractus mesopotamicus (Holmberg, 1887)
}

\author{
Eduardo Gianini Abimorad1, Dalton José Carneiro²
}

\begin{abstract}
RESUMO - Para melhorar a alimentação do pacu (Piaracatus mesopotamicus), é necessário conhecer o nível de aproveitamento dos ingredientes utilizados em suas dietas. Neste trabalho, inicialmente, foram analisados quatro métodos de coleta de fezes, em função da precisão e da versatilidade (dissecação, extrusão, Guelph e Guelph modificado), e o tempo entre as coletas de fezes nos sistemas de Guelph, por intermédio do coeficiente de digestibilidade da proteína bruta de uma dieta-referência para o pacu. Não houve diferença entre os métodos de coleta de fezes; já os intervalos de tempo das coletas apresentaram diferenças, podendo interferir nos resultados de digestibilidade da proteína. Em uma segunda etapa, para determinação dos coeficientes de digestibilidade da proteína e da energia de cinco concentrados protéicos de origem animal, cinco de origem vegetal e quatro energéticos, foram utilizadas rações elaboradas com $69,5 \%$ de uma dieta-referência, $30 \%$ do ingrediente teste e $0,5 \%$ de $\mathrm{Cr}_{2} \mathrm{O}_{3}$, utilizando o método de extrusão manual para a coleta de fezes. Os valores de digestibilidade da proteína da maioria dos alimentos apresentaram-se altos e não variaram estatisticamente, de 93,89 a $75,73 \%$ para o farelo de trigo e a farinha de penas, respectivamente. Entretanto, a farinha de sangue e a levedura apresentaram valores de digestibilidade da fração protéica significativamente inferiores $(57,72$ e $68,86 \%$, respectivamente). Os coeficientes de digestibilidade da energia dos alimentos variaram consideravelmente, apresentando altos valores (acima de $90 \%$ ) para o sorgo, o farelo de arroz e as sojas crua e tostada, e baixos valores (menores que 70\%) para as farinhas de vísceras e de sangue, os farelos de soja e de algodão e a levedura. Quanto aos métodos de coleta de fezes, conclui-se que qualquer um pode ser adotado para a determinação de digestibilidade, desde que sejam rigorosamente aplicados. De maneira geral, a maioria dos concentrados protéicos pode ser utilizada como ótimas fontes de proteína, com exceção da farinha de sangue e a levedura, enquanto os alimentos energéticos confirmaram-se como excelentes fontes de energia em dietas para o pacu.
\end{abstract}

Palavras-chave: pacu, Piaractus mesopotamicus, métodos de coleta de fezes, digestibilidade, proteína, energia

\section{Fecal Collection Methods and Determination of Crude Protein and of Gross Energy Digestibility Coefficients of Feedstuffs for Pacu, Piaractus mesopotamicus (Holmberg, 1887)}

ABSTRACT - To improve the pacu (Piaracatus mesopotamicus) feeding in the growth phase, it's necessary to know the digestibility of the ingredients used in his diets. Initially, four fecal collection methods were analyzed (dissection, stripping, Guelph and modified Guelph), based on precision and versatility and also the most efficient time among fecal collection of the Guelph sedimentation systems, through crude protein digestibility coefficient of pacu basic diet. There was no difference among the fecal collection methods while the intervals of time among the collections were significantly different, which may interfere in the protein digestibility results. In a second stage, five proteins concentrated of animal origin, five of vegetable origin and four energetic were studied for estimating protein and energy digestibility coefficients using the stripping method. The rations contained $69.5 \%$ of a reference diet, $30.0 \%$ of the ingredient test and $0.5 \%$ of $\mathrm{Cr}_{2} \mathrm{O}_{3}$. In a general way, crude protein digestibility coefficients were high and did not differ from the wheat meal (93.89\%) and feather flour (75.73\%), respectively. However, blood and yeast showed lower crude protein digestibility (57.72\% and 68.86\%), respectively. Gross energy digestibility coefficients varied considerably among the feedstuffs, showing high values (above $90 \%$ ) for the sorghum, rice meal and raw and toasted soy and lower values (smaller than 70\%) for poultry by-product and blood meal, soybean meal, cotton and yeast. However, with regard to the fecal collection methods, the results showed that anyone can be adopted with safety for digestibility determination, if used accurately. In a general way, most of protein concentrate can be used as a very good protein source, except for blood meal and the yeast. The energy concentrate revealed to be a source of energy in pacu diets.

Key Words: pacu, Piaractus mesopotamicus, fecal collection methods, digestibility, protein, energy

\footnotetext{
1 Zootecnista, Bolsista FAPESP 99/11323-6, Mestrando em Aquicultura, CAUNESP. Via de Acesso Prof. Paulo Donato Castellane S/N. CEP: 14884-900, Jaboticabal- SP- Brasil. E.mail: abimorad2002@yahoo.com.br

2 Zootecnista, Prof. Departamento de Zootecnia da FCAV- UNESP/Jaboticabal. Via de Acesso Prof. Paulo Donato Castellane S/N CEP: 14884-900, Jaboticabal- SP- Brasil. E.mail: daltonjc@caunesp.unesp.br
} 


\section{Introdução}

O fator mais importante para o bom desenvolvimento da criação de qualquer espécie animal é uma alimentação adequada. $\mathrm{O}$ cultivo de peixes e de outros organismos aquáticos tem participado de forma significativa e ascendente na produção de proteína animal; neste caso, a alimentação também não foge à regra, representando a maior parte dos custos operacionais, tornando os estudos de nutrição e alimentação na aquicultura, de extrema importância.

Nos últimos anos, o cultivo intensivo e semiintensivo de peixes tem sido crescente no Brasil, principalmente pelo interesse nas espécies nativas tropicais, como o pacu (Piaractus mesopotamicus) e o tambaqui (Colossoma macropomum), que apresentam grande potencial para a piscicultura, uma vez que possuem carne de excelente qualidade, além da facilidade na adaptação de criação em cativeiro.

O pacu, Piaractus mesopotamicus (Holmberg, 1887) - espécie bastante cultivada nas regiões Sudeste e Centro Oeste do país - possui ampla distribuição geográfica na América do Sul, sendo encontrado desde a Bacia dos Rios ParaguaiUruguai até a Bacia do Rio Prata. Na natureza, o pacu é um peixe rústico que utiliza alimentos bastante diversificados, variando as fontes em função da sazonalidade. Silva (1985) verificou que o tipo de alimento observado no estômago do pacu é constituído principalmente de folhas, resíduos vegetais e raramente restos e esqueletos de peixes e/ou moluscos e crustáceos, comprovando que se trata de uma espécie herbívora com preferência frugívora.

Para melhorar e otimizar a alimentação do pacu, é fundamental que se conheça o nível de aproveitamento dos ingredientes da dieta. Estudos sobre a digestibilidade da proteína e da energia dos principais produtos e subprodutos produzidos no Brasil e utilizados na elaboração de rações são de fundamental importância nos aspectos nutricional e econômico, resultando em maior precisão no balanceamento das dietas para organismos aquáticos.

Um método de coleta de fezes mais adequado para os estudos de digestibilidade em peixes é indispensável para que se obtenha precisão nos resultados (Austreng, 1978; Smith et al., 1980). Nestes estudos, o emprego de algumas metodologias, além de provocar estresse nos animais, pode acarretar outros problemas, como lixiviação de nutrientes na água e contaminação das fezes por tecidos e/ou substâncias do próprio animal, mascarando os valores obtidos (Utne, 1978). Os pesquisadores da área vêm estudando várias metodologias para coleta de fezes em peixes (dissecação intestinal, extrusão manual, sucção anal, pipetagem imediata na água, filtração contínua de água e decantação das fezes), com o intuito de averiguar as mais adequadas para padronização.

O presente trabalho foi conduzido com os objetivos de avaliar o método e o tempo de coleta de fezes mais eficientes e determinar os coeficientes de digestibilidade aparente (CDA) da fração protéica e da energia de 14 ingredientes mais utilizados na formulação de rações para o pacu.

\section{Material e Métodos}

Este estudo foi conduzido no Laboratório de Nutrição de Organismos Aquáticos, do Centro de Aqüicultura da UNESP, Campus de Jaboticabal, no período de fevereiro de 2000 a janeiro de 2001.

Para os ensaios sobre métodos e intervalos de coleta de fezes, foram utilizados 130 juvenis de pacu, com peso médio de $250 \mathrm{~g}$, distribuídos em 13 aquários de alimentação, constituídos de caixas de cimento amianto com capacidade de $500 \mathrm{~L}$ e abastecidas continuamente com água proveniente de poço artesiano em torno de $28^{\circ} \mathrm{C}$.

O primeiro método a ser analisado foi a dissecação intestinal. Após um período de 20 dias de adaptação, os peixes foram alimentados durante cinco dias com a dieta-referência (Tabela 1), acrescida de $0,5 \%$ de óxido de cromo. No quinto dia, dois aquários foram escolhidos aleatoriamente, e os peixes recémalimentados foram anestesiados com benzocaína $(0,05 \mathrm{~g} / \mathrm{L})$. Os 20 juvenis de pacu foram sacrificados e abertos lateralmente para retirada do conteúdo fecal presente no reto.

A porção distal do intestino (após a segunda válvula intestinal) foi retirada do peixe e colocada em uma placa de Pétri. Utilizando uma tesoura cirúrgica, o intestino foi aberto longitudinalmente e, com uma espátula, o conteúdo fecal foi retirado e transferido para outra placa de Pétri. Parte deste material foi encaminhada para secagem em estufa de circulação de ar forçado a $65^{\circ} \mathrm{C}$, até obtenção de peso constante. As fezes secas foram estocadas sob congelamento para análises posteriores. Outra parte deste material 
foi distribuída em cinco béqueres de vidro com $40 \mathrm{~mL}$ de água, para determinação da lixiviação da proteína na água e do intervalo de tempo mais preciso para a coleta nos sistemas de decantação. Uma amostra adicional (sexta) do conteúdo de fezes retirada após a divisão, sem ter contato com a água, foi considerada como controle. Decorridos os intervalos de tempo estabelecidos (30', 60', 120', 240' e 480'), o excesso de água foi retirado e as fezes, transferidas para placas de Pétri, para secagem também em estufa a $65^{\circ} \mathrm{C}$.

Os juvenis de pacu restantes foram redistribuídos em 12 aquários, em número de nove para cada um, para continuidade do ensaio.

O segundo método analisado foi o sistema de Guelph convencional, que consistiu no uso de aquários cilíndricos de fundo cônico com capacidade de 80 L. O abastecimento de água era contínuo e superior, enquanto o escoamento era pelo fundo, e as fezes que se decantavam no aquário transitavam pelo sistema de encanamentos laterais externos, onde permaneciam depositadas na extremidade inferior de uma coluna de água, até o momento da coleta. Registros de esfera foram utilizados para facilitar a coleta em tubos de vidro.

Após terem sido alimentados por cinco dias com uma dieta-referência contendo óxido de cromo, os juvenis de pacu, de seis aquários a cada vez, foram transferidos para os seis aquários de coleta que constituíram, cada um, uma repetição. Assim que começaram a aparecer as fezes nos tubos de vidro, decorridos intervalos de 30 minutos, foram repetidamente coletadas para evitar a lixiviação de nutrientes. Foi adotado o seguinte procedimento: fechava-se o registro do aquário coletor, retirava-se o tubo de vidro com as fezes já depositadas no fundo do mesmo, desprezava-se grande parte da água e tranferia-se o conteúdo do tubo para uma placa de Pétri, que permanecia em congelador até que se completasse a quantidade necessária para as análises químicas de proteína e de indicador.

No método de Guelph modificado, ocorria o mesmo procedimento. Apenas foi modificado o sistema de escoamento, que passou a ser realizado através de um cano lateral dentro do aquário coletor, que funcionava como sifão. Como as fezes ficavam depositadas na extremidade inferior dos aquários, foram colocados registros de esfera e pedaços de mangueira de látex para acoplagem de tubos de ensaio, a fim de facilitar a coleta.

O último método a ser estudado foi o da extrusão manual, em que, à semelhança do método da dissecação, cada peixe, depois de anestesiado, foi submetido a massagens na região abdominal, das nadadeiras ventrais em direção ao ânus, para a coleta das fezes, que foram depositadas em placas de Pétri e conservadas em congelador, para posterior secagem. As fezes dos peixes de cada aquário foram recolhidas para constituir cada repetição.

Para o ensaio de determinação dos coeficientes de digestibilidade da proteína e da energia dos alimentos, foram utilizados 255 juvenis de pacu, com peso médio de $310 \mathrm{~g}$, distribuídos em 17 aquários de alimentação constituídos de caixas de cimentoamianto com $500 \mathrm{~L}$ de capacidade. Estas caixas foram abastecidas continuamente por água proveniente de uma represa, com temperatura variando de 27 a $28^{\circ} \mathrm{C}$.

Tabela 1 - Formulação e composição estimada da dieta de referência ${ }^{1}$

Table 1 - Formulation and estimated composition of the reference diet

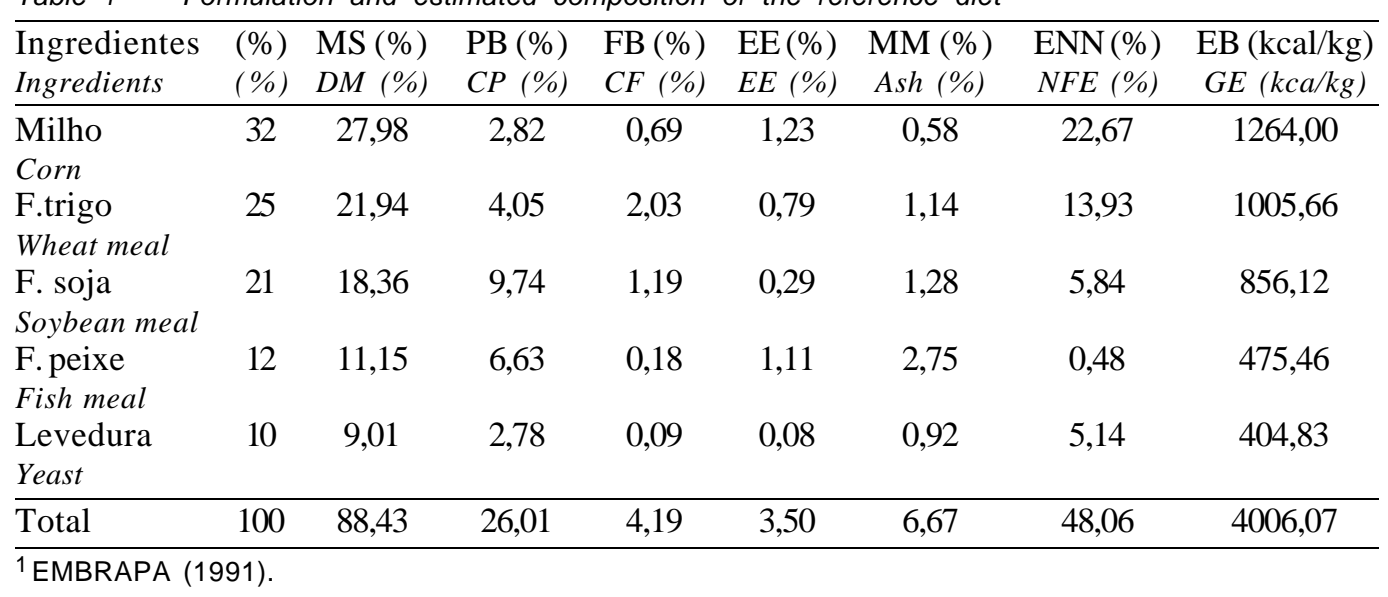

R. Bras. Zootec., v.33, n.5, p.1101-1109, 2004 
Na segunda etapa, o método escolhido para a coleta de fezes foi a extrusão manual. Após 20 dias de adaptação, os peixes foram alimentados durante cinco dias com as dietas-teste, que continham $69,5 \%$ da dieta-referência (Tabela 1), 30\% do ingrediente e $0,5 \%$ de óxido de cromo. No sexto dia, as fezes foram coletadas, secas e armazenadas para posteriores análises.

As análises dos teores de proteína bruta das rações e das fezes dos peixes foram realizadas no Laboratório de Nutrição de Organismos Aquáticos do CAUNESP e as quantidades de energia bruta, no LANA - Laboratório de Nutrição Animal, da Faculdade de Ciências Agrárias e Veterinárias de Jaboticabal - UNESP, por bomba calorimétrica de Parr, segundo a AOAC (1965).

Para avaliação dos métodos de coleta, foram utilizados os valores de digestibilidade da fração protéica observados para a dieta-referência, obtidos com as fezes coletadas em cada método.

Os ingredientes estudados consistiram de cinco concentrados protéicos de origem animal (farinha de peixe, farinha de carne e ossos, farinha de vísceras de frango, farinha de penas e farinha de sangue), cinco de origem vegetal (farelo de soja, soja crua integral, soja tostada, farelo de algodão e levedura) e quatro energéticos (farelo de trigo, farelo de arroz, milho e sorgo).

Os coeficientes de digestibilidade aparente (CDA) foram determinados por intermédio do método de coleta parcial das fezes dos peixes, utilizando-se o óxido de cromo como indicador inerte, de acordo com o método de digestão ácida, descrito por Furukawa \& Tsukahara (1966). Após a realização da análise quantitativa do óxido de cromo, e de posse dos valores de proteína e energia presentes nas dietas e nas fezes, os CDA foram estimados segundo Nose (1966), por intermédio da seguinte equação:

$$
\text { CDA }(\%)=100-100 \frac{\% \mathrm{Cr}_{2} \mathrm{O}_{3} \text { na dieta }}{\% \mathrm{Cr}_{2} \mathrm{O}_{3} \text { nas fezes }} \times \frac{\begin{array}{c}
\% \text { PB ou kcal } / \mathrm{kg} \mathrm{de} \\
\text { EB nas fezes }
\end{array}}{\begin{array}{r}
\% \text { PB ou kcal } / \mathrm{kg} \\
\text { de EB na dieta }
\end{array}}
$$

Para o cálculo da digestibilidade da proteína e da energia dos alimentos estudados, foi utilizada a seguinte equação, de acordo com Reigh et al. (1990): DAN $(\%)=(100 / 30) \times$ [ teste $-(70 / 100 \times$ referência $)]$ em que DAN = digestibilidade aparente da proteína ou da energia do alimento; Teste $=$ digestibilidade aparente da proteína ou da energia presente na dieta-teste; Referência = digestibilidade aparente da proteína ou da energia presente na dieta-referência.

Foi utilizado o delineamento inteiramente casualizado para avaliar os métodos de coletas de fezes e o intervalo das coletas nos sistemas de decantação, usados em estudos de digestibilidade. As médias foram submetidas à análise de variância e, em casos de significância, realizou-se a comparação das mesmas pelo teste Tukey.

Para avaliar os coeficientes de digestibilidade da fração protéica e da energia dos alimentos estudados, também foi utilizado o delineamento inteiramente casualizado, com 14 tratamentos, três repetições e 15 peixes por parcela. As médias foram submetidas à análise de variância e, apresentando significância, realizou-se a comparação das mesmas pelo teste Tukey.

\section{Resultados e Discussão}

Foram observadas algumas dificuldades para se obterem as quantidades mínimas de fezes necessárias para as análises de óxido de cromo e de proteína nas fezes, em duplicata, nos métodos da dissecação intestinal e da extrusão manual. Houve, forçosamente, redução no número de repetições (de 6 para 4) para esses tratamentos.

Os métodos de coleta de fezes não influenciaram ( $\mathrm{P}>0,05)$ os CDA da fração protéica da dietareferência para o pacu (Tabela 2).

Os valores dos desvios-padrão de cada média de digestibilidade confirmaram que os sistemas de Guelph tiveram maior variação que os métodos de dissecação e de extrusão, implicando em efeito depreciativo para determinação da digestibilidade, podendo mascarar os resultados, em decorrência de fatores como a lixiviação de nutrientes e de óxido de cromo e a contaminação das fezes por muco, escamas e até mesmo partículas de alimentos regurgitadas, como foi observado por Ramsay et al. (2000). O método de extrusão manual apresentou menor desvio-padrão das médias, sem haver necessidade de sacrificar os peixes. Sullivan \& Reigh (1995) afirmam que o método de extrusão manual evita o contato das fezes com a água, tornando-o mais preciso que os demais. Devido a este fato e à versatilidade, determinaram-se os CDA dos alimentos.

Segundo Spyridakis et al. (1989), há tendência de os métodos que utilizam material fecal naturalmente evacuado na água apresentarem valores maiores de 
digestibilidade, em razão da lixiviação de nutrientes na água, como se essa fração de nutriente tivesse sido aproveitada pelo peixe. Entretanto, no presente estudo, os métodos de Guelph e de Guelph modificado apresentaram valores de digestibilidade aparentemente menores, apesar de não diferirem estatisticamente dos observados nos métodos em que as fezes não tiveram contato com a água. Se estas pequenas diferenças fossem estatisticamente significativas, poderiam ser explicadas por dois prováveis motivos: primeiro, pela contaminação do material fecal, considerando-se que pequena quantidade de escamas e muco poderia ter se juntado às fezes, nos tubos coletores, mesmo que houvesse separação pelo menos das escamas após a secagem; segundo, também seria possível, de acordo com Jones \& De Silva (1997), que, juntamente com a inevitável perda de proteína nesses métodos, também tivesse ocorrido lixiviação de pequena parte do óxido de cromo, diminuindo ligeiramente o valor da digestibilidade. Silva et al. (1999) também não encontraram diferenças significativas entre os métodos de dissecação intestinal e de Guelph, na determinação da digestibilidade de alguns alimentos para o tambaqui.

A tendência de os valores de digestibilidade obtidos por extrusão manual serem maiores que os de dissecação do reto e pelo Guelph também foi observada

Tabela 2 - Resultado da análise estatística dos coeficientes de digestibilidade da proteína para os diferentes métodos de coleta de fezes

Table 2 - Statistical analysis result of protein digestibility coefficients for the different fecal collection methods

\begin{tabular}{|c|c|}
\hline $\begin{array}{l}\text { Tratamentos } \\
\text { Treatments }\end{array}$ & $\begin{array}{c}\text { Digestibilidade da PB (\%) } \\
C P \text { digestibility }(\%)\end{array}$ \\
\hline Guelph (Guelph) & $81,44 \pm 3,53$ \\
\hline Guelph modificado & $82,83 \pm 2,55$ \\
\hline Modified Guelph & \\
\hline $\begin{array}{l}\text { Extrusão manual } \\
\text { Stripping }\end{array}$ & $86,66 \pm 0,76$ \\
\hline Dissecação & $84,52 \pm 0,38$ \\
\hline Dissection & \\
\hline $\begin{array}{l}\text { Valor de } \mathrm{F} \\
\text { F value }\end{array}$ & $3,23^{\mathrm{NS}}$ \\
\hline $\begin{array}{l}\text { Coeficiente de variação (\%) } \\
\text { Coefficient of variation }(\%)\end{array}$ & 3,13 \\
\hline
\end{tabular}

R. Bras. Zootec., v.33, n.5, p.1101-1109, 2004 por Ramsay et al. (2000), quando compararam os métodos de extrusão manual e de sedimentação, para determinação de digestibilidade. Os autores atribuíram essa diferença ao movimento desigual do óxido de cromo no trato digestivo. Em outro estudo, Austreng (1978) relatou que, durante a dissecação do peixe, poderiam ocorrer, ocasionalmente, pressão e injurias nas vísceras provocando, dessa forma, adição de nitrogênio endógeno (muco e células epiteliais) às fezes, diminuindo os valores de digestibilidade da proteína.

Os resultados do ensaio realizado para a determinação do melhor intervalo das coletas de fezes nos métodos com defecação natural, de forma que ocorressem menores perdas de nutrientes por lixiviação, são mostrados na Tabela 3. Os intervalos das coletas de fezes para os sistemas de decantação apresentaram diferentes efeitos $(\mathrm{P}<0,05)$ na determinação do $\mathrm{CDA}$ da proteína. Entretanto, a comparação das médias pelo teste Tukey não mostrou diferenças estatísticas significativas.

Observando as médias dos CDA da proteína da dieta para os diferentes intervalos das coletas de fezes, houve aumento nos coeficientes de digestibilidade, com o avanço do intervalo das coletas, indicando que possivelmente ocorreram pequenas

Tabela 3 - Resultado da análise estatística dos coeficientes de digestibilidade da proteína para cada intervalo de tempo de recolhimento de fezes

Table 3 - Statistical analysis result of protein digestibility coefficients for each interval feces collection time

\begin{tabular}{lc}
\hline $\begin{array}{l}\text { Tratamentos } \\
\text { Treatments }\end{array}$ & $\begin{array}{c}\text { Digestibilidade da PB (\%) } \\
\text { CP digestibility (\%) }\end{array}$ \\
\hline$(1) 0$ & $82,14 \pm 3,53 \mathrm{a}^{1}$ \\
$(2) 30^{\prime}$ & $83,15 \pm 1,06 \mathrm{a}$ \\
$(3) 60^{\prime}$ & $85,05 \pm 1,30 \mathrm{a}$ \\
$(4) 120^{\prime}$ & $84,31 \pm 0,77 \mathrm{a}$ \\
$(5) 240^{\prime}$ & $85,87 \pm 1,10 \mathrm{a}$ \\
$(6) 480^{\prime}$ & $85,90 \pm 0,92 \mathrm{a}$ \\
\hline Valor de F & $3,08 *$ \\
$F$ value & \\
\hline
\end{tabular}

Coeficiente de variação(\%) 2,05

Coefficient of variation (\%)

* Significativo $(\mathrm{P}<0,05)$ (Significant $[P<.05])$.

1 Médias seguidas de mesma letra não diferem $(P>0,05)$ pelo teste Tukey.

${ }^{1}$ Means followed by the same letter did not differ $(P>.05)$ by Tukey test. \pm Desvio-padrão ( \pm standard deviation). 
perdas de nutrientes por lixiviação.

Comparando-se com os resultados de digestibilidade da proteína da dieta, obtidos pelos sistemas Guelph, os valores apresentaram-se pouco divergentes, indicando que este tipo de ensaio pode não representar integralmente os sistemas de decantação. De outra forma, os valores médios sugerem que, nos sistemas de decantação de fezes, o intervalo das coletas poderia ser em torno de 30 minutos, para evitar-se a lixiviação do nutriente e a superestimativa dos valores de digestibilidade. As fezes apresentaram-se em quantidades muito pequenas e até estavam ausentes nos tubos coletores nos períodos anteriores a 30 minutos.

Estão apresentados na Tabela 4 os resultados dos coeficientes de digestibilidade aparente (CDA) da proteína e da energia bruta, mostrando diferenças $(\mathrm{P}<0,05)$ entre os alimentos estudados.

Os valores médios de digestibilidade da proteína dos alimentos, de maneira geral, apresentaram-se altos, não variando estatisticamente (entre 93,89 e $75,73 \%$, observados para o farelo de trigo e a farinha de penas, respectivamente). Isto pode ser justificado pelo hábito alimentar do pacu, que, segundo Silva (1985), é especificamente frugívoro-herbívoro, mas pode ser considerado onívoro de caráter oportunista, variando a alimentação com a sazonalidade.

A temperatura da água, que se apresentou em torno de $28^{\circ} \mathrm{C}$, considerada ideal para o desenvolvimento do pacu (Carneiro, 1990), também pode ter contribuído para obtençãodesses altos coeficientes de digestibilidade para a fração protéica dos alimentos.

São compreensíveis os valores significativamente mais baixos para a levedura e a farinha de sangue. Sampaio et al. (2000) estudaram a digestibilidade da proteína de alguns alimentos para a tilápia do Nilo e obtiveram para a farinha de sangue o coeficiente de $50,69 \%$, que condiz com o baixo valor encontrado para o pacu, no presente trabalho.

Storebakken et al. (1998), quando substituíram parte da farinha de peixe pela levedura em dietas para salmão, também encontraram menor coeficiente de digestibilidade para proteína da dieta, atribuindo este resultado à baixa digestibilidade de certos aminoácidos contidos na levedura. De acordo com Padua (1996), a levedura poderia substituir a farinha de peixe como fonte protéica de uma dieta até o nível de $75 \%$, sem interferir nos parâmetros de desempenho para juvenis de pacu.

Comparando os resultados dos coeficientes de digestibilidade da proteína com os determinados por Pires (1998), também para o pacu, observou-se que a soja crua e a tostada, o farelo de algodão, o milho e o farelo de arroz apresentaram resultados equivalentes aos do presente trabalho $(84,23 ; 89,40 ; 86,99 ; 85,62 \mathrm{e}$ $82,41 \%$, respectivamente), embora com a coleta de fezes pelo método de Guelph modificado. Em contrapartida, a farinha de vísceras, o farelo de soja e a levedura apresentaram valores superiores $(94,13$; 90,04 e 90,27\%, respectivamente) e o farelo de trigo, o sorgo e a farinha de peixe, inferiores aos encontrados no presente trabalho $(81,71 ; 84,04$ e $81,59 \%$, respectivamente). Dessa forma, pode-se deduzir que o método de Guelph modificado promoveria maior variação nos resultados, pelo menos para alguns alimentos.

Em um trabalho com bagre do canal, Khan (1994) observou que a farinha de peixe, o farelo de soja e o farelo de arroz foram mais digestíveis que o milho, o qual apresentou alto teor de fibra e amido, e as vísceras de frango, que não foram submetidas a um processo para melhorar seu valor nutricional. $\mathrm{O}$ autor também relatou que os melhores valores de digestibilidade se devem, principalmente, ao conteúdo e qualidade da proteína e à composição de aminoácidos dos alimentos. Porém, neste estudo realizado com o pacu, não foram observadas grandes diferenças na digestibilidade da proteína desses alimentos, embora o conteúdo de energia do farelo de soja e da farinha de vísceras (Tabela 4) apresentasse valores relativamente baixos.

Pode-se observar também que as médias dos CDA da energia dos alimentos variaram consideravelmente $(\mathrm{P}<0,05)$, de 93,36 a $45,77 \%$, valores observados para o sorgo e a levedura, respectivamente (Tabela 4).

A farinha de peixe, muitas vezes, é utilizada como fonte padrão de proteína para comparação com outros alimentos (Storebakken et al., 1998). No presente estudo, entre os alimentos protéicos de origem animal, as maiores médias de digestibilidade da proteína e da energia foram observadas, respectivamente, para a farinha de carne e ossos $(88,60$ e $83,98 \%)$ e a farinha de peixe $(88,40$ e $78,14 \%)$. Sullivan \& Reigh (1995) estudaram a digestibilidade de alimentos para $\mathrm{o}$ striped bass (Morone sp) e Gaylord \& Gatlin III (1996), para o red drum (Scienops ocellatus), obtendo também valores de digestibilidade (principalmente da energia) relativamente altos para a farinha de carne e ossos e a farinha de peixe. Considerando-se que, no Brasil, a qualidade desses alimentos varia consideravelmente,

\section{R. Bras. Zootec., v.33, n.5, p.1101-1109, 2004}


os resultados mostraram que a farinha de carne e ossos utilizada neste estudo foi de boa qualidade, comparada à farinha de peixe nacional, que geralmente é elaborada com resíduos de pescado.

Os altos valores de digestibilidade da energia observados para o sorgo $(93,36 \%)$, o milho $(86,69 \%)$ e o farelo de trigo $(81,16 \%)$ são compreensíveis, por serem alimentos energéticos e terem elevados teores de carboidratos. O farelo de arroz, as sojas integrais, crua e tostada e a farinha de carne e ossos apresentaram também altos coeficientes de digestibilidade da energia, provavelmente em decorrência do elevado teor de gordura desses alimentos. Estes fatos confirmam que o pacu é uma espécie que sintetiza eficientemente os carboidratos e os lipídios, como fonte de energia, podendo poupar proteína catabolizada para obtenção de energia e melhorar sua utilização para formação de tecido muscular, em um processo conhecido como poupador de proteína.

De modo geral, os concentrados protéicos estudados apresentaram-se como boas fontes de proteína para o pacu, considerando que, apesar de seus valores brutos

Tabela 4 - Valores médios de proteína bruta $(\mathrm{PB})$ e energia bruta (EB), digestibilidade aparente da fração protéica (DaPB) e da energia (DaEB), proteína digestível (PD) e energia digestível (ED) dos alimentos para o pacu

Table 4 - Average values of crude protein (CP) and gross energy (GE), protein apparent digestibility (AdCP), energy apparent digestibility (AdGE), digestible protein (DP) and digestible energy (DE) of feedstuffs for pacu

\begin{tabular}{|c|c|c|c|c|c|c|}
\hline \multirow[b]{2}{*}{$\begin{array}{l}\text { Alimentos } \\
\text { Feedstuffs }\end{array}$} & \multicolumn{3}{|c|}{$\begin{array}{l}\text { Proteína } \\
\text { Protein } \\
\end{array}$} & \multicolumn{3}{|c|}{$\begin{array}{l}\text { Energia } \\
\text { Energy }\end{array}$} \\
\hline & $\begin{array}{l}\mathrm{PB}(\%) \\
C P(\%)\end{array}$ & $\begin{array}{l}\mathrm{DaPB}(\%) \\
\operatorname{AdCP}(\%)\end{array}$ & $\begin{array}{l}\mathrm{PD}(\%) \\
D P(\%)\end{array}$ & $\begin{array}{l}\mathrm{EB}(\mathrm{kcal} / \mathrm{kg}) \\
G E(\mathrm{kcal} / \mathrm{kg})\end{array}$ & $\begin{array}{l}\operatorname{DaEB}(\%) \\
A d G E(\%)\end{array}$ & $\begin{array}{l}\mathrm{ED}(\mathrm{kcal} / \mathrm{kg}) \\
D E(k c a / \mathrm{kg})\end{array}$ \\
\hline $\begin{array}{l}\text { Farinha de penas } \\
\text { Feather meal }\end{array}$ & 79,02 & $75,73 \pm 11,33 \mathrm{abc}^{1}$ & 59,84 & 5227,41 & $79,52 \pm 8,95 b^{1}$ & 4156,84 \\
\hline $\begin{array}{l}\text { Farinha de peixe } \\
\text { Fish meal }\end{array}$ & 58,30 & $88,40 \pm 3,41 \mathrm{a}$ & 51,54 & 3833,00 & $78,14 \pm 1,40 \mathrm{bc}$ & 2995,11 \\
\hline $\begin{array}{l}\text { Farinha de vísceras } \\
\text { Poultry by-product }\end{array}$ & 58,60 & $83,40 \pm 5,21 \mathrm{ab}$ & 48,87 & 4489,03 & $69,99 \pm 5,81 \mathrm{bcd}$ & 3141,87 \\
\hline $\begin{array}{l}\text { Farinha de sangue } \\
\text { Blood meal }\end{array}$ & 73,44 & $57,72 \pm 7,14 \mathrm{c}$ & 42,39 & 4831,75 & $67,41 \pm 3,71 \mathrm{~cd}$ & 3257,08 \\
\hline $\begin{array}{l}\text { Farelo de soja } \\
\text { Soybean meal }\end{array}$ & 44,59 & $81,14 \pm 6,74 \mathrm{ab}$ & 36,18 & 4203,70 & $63,68 \pm 2,70 \mathrm{~d}$ & 2676,92 \\
\hline $\begin{array}{l}\text { Farinha de carne e ossos } \\
\text { Meat and bone meal }\end{array}$ & 40,58 & $88,60 \pm 3,62 \mathrm{a}$ & 35,95 & 3022,53 & $83,98 \pm 2,31 \mathrm{ab}$ & 2538,32 \\
\hline $\begin{array}{l}\text { Soja tostada } \\
\text { Soybean - whole, toasted }\end{array}$ & 37,06 & $92,04+2,74 \mathrm{a}$ & 34,11 & 5438,34 & $91,45 \pm 2,26 a b$ & 4973,36 \\
\hline $\begin{array}{l}\text { Farelo de algodão } \\
\text { Cottonseed meal }\end{array}$ & 38,90 & $86,00 \pm 1,83 a b$ & 33,45 & 4268,43 & $59,55 \pm 4,54 \mathrm{~d}$ & 2541,85 \\
\hline $\begin{array}{l}\text { Soja crua } \\
\text { Soybean - whole, raw }\end{array}$ & 39,58 & $83,46 \pm 5,11 \mathrm{ab}$ & 33,03 & 5086,27 & $92,71 \pm 3,22 \mathrm{a}$ & 4715,48 \\
\hline $\begin{array}{l}\text { Levedura } \\
\text { Alcohool yeast }\end{array}$ & 40,13 & $68,86 \pm 14,68 \mathrm{bc}$ & 27,63 & 3837,37 & $45,77 \pm 3,78 \mathrm{e}$ & 1756,36 \\
\hline $\begin{array}{l}\text { Farelo de trigo } \\
\text { Wheat meal }\end{array}$ & 16,20 & $93,89 \pm 1,33$ a & 15,21 & 4081,90 & $81,16 \pm 1,03 \mathrm{ab}$ & 3312,87 \\
\hline $\begin{array}{l}\text { Sorgo } \\
\text { Sorghum }\end{array}$ & 14,37 & $92,93 \pm 1,96 \mathrm{a}$ & 13,35 & 3719,10 & $93,36 \pm 4,02 \mathrm{a}$ & 3472,15 \\
\hline $\begin{array}{l}\text { Farelo de arroz } \\
\text { Rice meal }\end{array}$ & 13,40 & $80,82 \pm 3,94 \mathrm{ab}$ & 10,83 & 4541,45 & $92,73 \pm 2,40 \mathrm{a}$ & 4211,29 \\
\hline $\begin{array}{l}\text { Milho } \\
\text { Corn - dent, yellow }\end{array}$ & 8,79 & $84,38+11,00 \mathrm{ab}$ & 7,42 & 3996,90 & $86,69 \pm 2,69 \mathrm{ab}$ & 3464,91 \\
\hline $\begin{array}{l}\text { Valor de } \mathrm{F} \\
F \text { value } \\
\end{array}$ & & $8,11 * *$ & & & $39,25 * *$ & \\
\hline $\begin{array}{l}\text { Coeficiente de variação }(\%) \\
\text { Coefficient of variation }(\%)\end{array}$ & & 8,23 & & & 5,14 & \\
\hline
\end{tabular}

R. Bras. Zootec., v.33, n.5, p.1101-1109, 2004 
serem relativamente baixos, tiveram boa digestibilidade desse nutriente, proporcionando níveis satisfatórios de proteína digestível.

O farelo de soja é a fonte protéica mais utilizada na alimentação animal. Neste estudo, foi observado alto valor de digestibilidade para a fração protéica $(81,14 \%)$ e baixo para a energia $(63,68 \%)$, que condiz com os resultados encontrados por Hanley (1987), Sullivan \& Reigh (1995) e Gaylord \& Gatlin III (1996). Para a fase de crescimento do pacu, no presente trabalho, as sojas integrais crua e tostada $(83,46 \%$ e $92,04 \%$, respectivamente) apresentaram digestibilidade melhores que o farelo de soja.

Sullivan \& Reigh (1995) observaram valores de digestibilidade da energia do farelo de trigo, do farelo de arroz e do milho, para o striped bass, de 54,5; 47,0 e $40,7 \%$, respectivamente, mostrando que peixes carnívoros não aproveitam adequadamente alimentos desta natureza. Os alimentos energéticos apresentaram, para o pacu, ótimos coeficientes de digestibilidade, tanto para proteína como para energia (acima de 80\%), permitindo sua inclusão em dietas comerciais como fonte de energia mais barata.

O farelo de trigo e o sorgo, apesar de energéticos e com altos teores de carboidratos, foram os alimentos que apresentaram altíssimos coeficientes de digestibilidade da fração protéica, mostrando sua grande qualidade de proteína. Todavia, por conterem baixos teores de proteína bruta, apresentaram, conseqüentemente, baixas concentrações de proteína digestível (Tabela 4). O milho e o farelo de arroz também apresentaram concentrações de proteína digestível coerentes com sua composição química.

As farinhas de penas e de sangue apresentaram concentrações de proteína digestível relativamente altas, mas principalmente por seu alto teor de proteína bruta. Segundo Andriguetto et al. (1985), as proteínas desses alimentos são de baixa qualidade, o que as torna pouco digestíveis para os outros monogástricos. No entanto, pela sua disponibilidade e baixo custo, estudos sobre a potencialidade de utilização desses alimentos em rações para o pacu deveriam ter continuidade, com avaliações de seu desempenho e custo de arraçoamento, de forma a contribuir para a nutrição mais econômica desse peixe.

Os alimentos que apresentaram maiores concentrações de energia digestível para o pacu foram: a soja tostada $(4973,36 \mathrm{kcal} / \mathrm{kg})$, a soja crua $(4715,48 \mathrm{kcal} / \mathrm{kg})$ e o farelo de arroz $(4211,29 \mathrm{kcal} / \mathrm{kg})$, em razão dos altos teores de gordura e coeficientes de digestibilidade da energia. A farinha de penas também apresentou alta concentração de energia digestível $(4156,84 \mathrm{kcal} / \mathrm{kg})$, principalmente em decorrência do elevado teor de energia bruta.

Entre os alimentos protéicos de origem vegetal, a soja tostada apresentou os melhores coeficientes de digestibilidade, tanto para a fração protéica como para a energia, mostrando que o tratamento térmico usado para inibição dos fatores antinutricionais, de acordo com Stech (1999), pode ter interferido na digestibilidade, principalmente da proteína, nesse tipo de alimento para o pacu.

De acordo com Hepher (1988), os peixes não têm verdadeira exigência em proteínas, mas sim em aminoácidos essenciais, cuja forma mais eficaz e econômica de supri-la resume-se na combinação de alimentos com proteínas mais digestíveis, de alta qualidade, e custo acessível. A relação energia digestível/proteína de uma dieta também é de extrema importância (Kubitza, 1999), pois, quando estiver baixa, o peixe utilizará a proteína dietética como suplemento energético, e quando estiver alta, poderá ocorrer maior acúmulo de gordura corporal.

Espera-se que estes resultados possam dar início à confecção de tabelas nacionais de utilização de nutrientes dos ingredientes mais empregados em dietas para o pacu, uma vez que os dados de outros países não refletem os hábitos alimentares e as condições de cultivo de peixes da América Latina, e nem mesmo a composição bromatológica de alguns alimentos.

\section{Conclusões}

Todos os métodos de coleta de fezes estudados podem ser adotados, com segurança, para determinação dos coeficientes de digestibilidade da fração protéica dos alimentos para o pacu, na fase de crescimento, desde que usados de forma criteriosa.

O intervalo das coletas de fezes para o estudo de digestibilidade, utilizando-se os sistemas de Guelph, não deveria ultrapassar 30 minutos.

De maneira geral, a maioria dos concentrados protéicos pode ser utilizada como ótimas fontes de proteína, com exceção da farinha de sangue e da levedura. Os alimentos energéticos confirmaram-se como excelentes fontes de energia em dietas para o pacu. 


\section{Literatura Citada}

ANDRIGUETTO, J.M.; PERLY, L.; MINARDI, I. et al. Nutrição animal. 4.ed. São Paulo: Nobel, 1985. v.1, p.71-134.

ASSOCIATION OF OFFICIAL AGRICULTURE CHEMISTS - AOAC. Official methods of analyses of the Association of Agriculture Chemists. Washington, D.C.: $1965.937 \mathrm{p}$.

AUSTRENG, E. Digestibility determination in fish using chromic oxide marking and analysis of from different segments of the gastrointestinal tract. Aquaculture, v.13, p.265-272, 1978.

CARNEIRO, D.J. Efeito da temperatura na exigência de proteína e energia para alevinos de pacu Piaractus mesopotamicus (Holmberg, 1887). São Carlos: Universidade Federal de São Carlos, 1990. 59p. Tese (Doutorado em Ecologia e Recursos Naturais) Universidade Federal de São Carlos, 1990.

EMPRESA BRASILEIRA DE PESQUISA AGROPECUÁRIA - EMBRAPA. Tabela de composição química e valores energéticos de alimentos para suínos e aves. 3.ed. Concórdia, 1991. 97p.

FURUKAWA, A.; TSUKAHARA, H. On the acid digestion for the determination of chromic oxide as an index substance in the study of digestibility of fish feed. Bulletin of the Japanese Society of Scientific Fisheries, v.32, n.6, p.502-506, 1966.

GAYLORD, T.G.; GATLIN III, D.M. Determination of digestibility coefficients of various feedstuffs for red drum Sciaenops ocellatus. Aquaculture, v.139, p.303-314, 1996.

HANLEY, F. The digestibility of foodstuffs and the effects of feeding selectivity on digestibility determinations in tilapia, Oreochromis niloticus (L). Aquaculture, v.66, p.163-179, 1987.

HEPHER, B. Nutrition of pond fishes. Cambridge: Cambridge University Press, 1988. p.48-64.

JONES, L.P.; De SILVA, S.S. Influence of differential movement of the marker chromic oxide and nutrients on digestibility estimations in the Australian freshwater crayfish Cherax destructor. Aquaculture, v.154, p.323-336, 1997.

KHAN, M.S. Apparent digestibility coefficients for common feed ingredients in formulated diets for tropical catfish, Mystus nemurus (Cuvier \& Valenciennes). Aquaculture and Fisheries Management, v.25, n.2, p.167-174, 1994.

KUBITZA, F. Nutrição e alimentação dos peixes cultivados. 3.ed. Jundiaí: Degaspari, 1999. p.14-65.

NOSE, T. Recents advances in the study of fish digestion in Japan. In: SYMPOSIUM ON FEEDING TROUT AND SALMON CULTURE, SC II-7., 1966, Belgrade. Proceedings... Belgrade: EIFAC, 1966. p.17.

PADUA, D.M.C. Utilização da levedura alcoólica (Saccharomyces cerevisiae) como fonte protéica na alimentação de juvenis de pacu (Piaracatus mesopotamicus): aspectos metabólicos e de desempenho produtivo. Jaboticabal: Universidade Estadual Paulista, 1996. 111p. Dissertação (Mestrado em Aqüicultura) - Universidade Estadual Paulista, 1996.

PIRES, C.T. Determinação da digestibilidade aparente da proteína e da matéria seca dos principais alimentos para o pacu, Piaracatus mesopotamicus (Holmberg, 1887). Jaboticabal: Universidade Estadual Paulista, 1998. 44p. Monografia (Trabalho de Graduação em Zootecnia) - Universidade Estadual Paulista, 1998.

RAMSAY, J.M.; CASTELL, J.D.; ANDERSON, D.M. et al. Effects of fecal collection methods on estimation of digestibility of protein feedstuffs by "winter flounder". North American Journal of Aquaculture, v. 66, p. 168$173,2000$.

REIGH, R.C.; BRADEN, S.L.; CRAIG, R.J. Apparent digestibility coefficients for common feedstuffs in formulated diets for red swamp crayfish, Procambarus clarkii. Aquaculture, v.84, p.321-334, 1990.

SAMPAIO, F.G.; HISANO, H.; YAMAKI, R.A. et al. Digestibilidade aparente pela tilápia do Nilo (Oreochromis niloticus) das farinhas de peixe nacional e importada e das farinhas de sangue tostada e spray-dried. In: SIMPÓSIO BRASILEIRO DE AQÜICULTURA, 11., 2000, Florianópolis. Anais... Florianópolis: ABRAq, 2000. 1 CD-ROM.

SILVA, A.J. Regime alimentar do pacu, Colossoma mitrei (Berg, 1895) no Pantanal de Mato Grosso em relação à flutuação do nível da água. In: CONGRESSO BRASILEIRO DE ZOOLOGIA, 12., 1985, Campinas. Anais... Campinas: 1985. p.179

SILVA, J.A.M.; PEREIRA FILHO, M.; OLIVEIRA PEREIRA, M.I. Digestibility of seeds consumed by tambaqui (Colossoma macropomum Cuvier, 1818): na experimental approach. In: VAL, A.L.; ALMEIDA VAL, V.M.F. (Eds.). Biology of tropical fishes. Manaus: INPA, 1999. p.137- 148.

SMITH, R.R; PETERSON, M.C.; ALLRED, A.C. Effect of leaching on apparent digestion coefficients of feedstuffs for salmonids. The Progressive Fish Culturist, v.42, n.2, p.195-199, 1980

SPYRIDAKIS, P.; METAILLER, R.; GABAUDAN, J. et al. Studies on nutrient digestibility in European sea bass (Dicentrarchus labrax). 1. Methodological aspects concerning faeces collection. Aquaculture, v.77, p.61-70, 1989.

STECH, M.R. Utilização de soja integral processada em dieta para o crescimento de pacu,Piaractus mesopotamicus (Holmberg, 1887). Jaboticabal: Universidade Estadual Paulista, 1999. 90p. Dissertação (Mestrado em Produção Animal) - Universidade Estadual Paulista, 1999.

STOREBAKKEN, T.; KVIEN, I.S.; SHEARER, K.D. et al. The apparent digestibility of diets containing fish meal, soybean meal or bacterial meal fed to Atlantic salmon, Salmo solar: evaluation of different faecal collection methods. Aquaculture, v.169, p.195-210, 1998.

SUlLIVAN, A.J.; REIGH, R.C. Apparent digestibility of selected feedstuffs in diets for hybrid striped bass (Morone saxatilis female $\mathrm{x}$ Morone chrysops male). Aquaculture, v.138, p.313-322, 1995.

UTNE, F. Standart methods and terminology in finfish nutrition. In: SIMPOSIUM OF FINFISH NUTRITION AND FISH FEED TECHNOLOGY, 1978, Hamburg. Proceedings... Hamburg: EIFAC/FAO, 1978. R-1, 14p.

R. Bras. Zootec., v.33, n.5, p.1101-1109, 2004

Recebido em: 30/04/03

Aceito em: 08/12/03 